\title{
Study on Relative Resource Carrying Capacity in Northwest China Based on Improved Model
}

\section{-A Case Study in Baoji, China}

\author{
Pei Wang1, Langong Hou ${ }^{1 *}$, Xiaoqin $\mathrm{He}^{2}$ \\ ${ }^{1}$ School of Civil Engineering and Architecture, Southwest University of Science and Technology, Mianyang, China \\ ${ }^{2}$ Huzhou Normal University, Huzhou, China \\ Email: Angelawpwy@163.com, *soundskyhlg@163.com
}

How to cite this paper: Wang, P., Hou, L. G., \& He, X. Q. (2021). Study on Relative Resource Carrying Capacity in Northwest China Based on Improved Model. Journal of Human Resource and Sustainability Studies, 9, 369-383.

https://doi.org/10.4236/jhrss.2021.92023

Received: May 12, 2021

Accepted: June 27, 2021

Published: June 30, 2021

Copyright $\odot 2021$ by author(s) and Scientific Research Publishing Inc. This work is licensed under the Creative Commons Attribution International License (CC BY 4.0).

http://creativecommons.org/licenses/by/4.0/

\section{(c) (i) Open Access}

\begin{abstract}
Based on the theory of sustainable development, in order to promote the sustainable development of population-nature-economy-society-environment in Northwest China. Taking advantage of the traction effect of superior resources and the binding effect of inferior resources, the factors under natural resources in the study area are expanded, and social and environmental factors are added to improve the traditional resource carrying capacity model. Using the improved theory and research method of relative resource carrying capacity, taking the whole country and Shaanxi Province as reference areas, the relative resource carrying capacity of Baoji City from 2010 to 2019 was calculated, and the evolution of these three factors was analyzed. The results show that: 1) Compared with the overload of resources carrying capacity in Baoji under the traditional model, the improved resource carrying capacity model shows that the relative resource carrying capacity of Baoji City is still in a surplus state. 2) The contribution rate of social resources carrying capacity and economic resources carrying capacity in Baoji city is on the rise, which is the main carrying resource of Baoji city's population. The contribution rate of natural resources carrying capacity and environmental resources carrying capacity to comprehensive resources carrying capacity is declining, and the overall resources carrying capacity is relatively balanced. 3) The comprehensive carrying capacity index of Baoji City shows a downward trend, which indicates that the surplus scale of resource carrying capacity of Baoji City is shrinking.
\end{abstract}

\section{Keywords}

Baoji City, Improved Model, Relative Resource Carrying Capacity 


\section{Preface}

Resource carrying capacity generally refers to the important supporting and driving capacity of the utilization quantity and environmental quality of natural resources in a geographical country or autonomous region for the basic quality survival and sustainable development of the whole population in the geographical space [Zhang, 2000]. The reserve of natural resources and the capacity of natural environment in a region determine the population carrying capacity of the region in a certain period. However, the intergenerational carrying capacity of human resources often has a certain economic value. If it exceeds this value, it will destroy the balance between man and the environment and cause the deterioration of the ecological environment. If the social population in a region exceeds the population that the environmental resources in the region can carry, it will not only affect the contemporary or intergenerational development of the region, but also directly leads to the serious collapse of the ecological system of the whole human society. Therefore, the use of resources and economic growth should keep a certain proportion of the bearing relationship with the population [Lu, 2014]. The carrying capacity of resources plays a vital role in a country's economic and social development. It is necessary to control the bearing range of the carrying capacity of resources in the process of urban construction and development, so as to effectively guarantee the safe and sustainable development of national socialist economy and public resources. In China, the research and development of resource utilization carrying capacity started earlier. In the initial research, the resource carrying capacity was taken as an isolated object, and the influencing factors were relatively single when selecting indicators, and most of them took natural resources as influencing factors. Thus, many achievements [Wei \& Chang, 2014; Chen, Tong, \& Zeng, 2008; Han, Liu, \& Yang, 2008; Zhao, Zhou, \& Sui, 2009; Hou \& Sun, 2002] are obtained. However, the impact of natural resources on human beings is not only an independent stock of natural resources, but a resource complex combining human science and technology with human resources. Therefore, there is a scientific basis for extending the influencing factors to nature-economy-society. Under the in-depth study of scholars, Considering the matching degree and complementarity among nature, economy, society and environment, the scope of influencing factors is expanded and various related factors are comprehensively considered, and the method of relative resource carrying capacity is used. Compared with traditional research on resource carrying capacity, one or more areas larger than the research area are taken as reference objects. It is more open in perspective, so as to obtain the carrying capacity of population resources in the study area. Huang Ningsheng [Huang \& Kuang, 2000] first proposed the relative resource carrying capacity, and added economic factors, which changed the traditional evaluation model of natural resources as a single influencing factor. Broaden the research scope of relative resource carrying capacity, and use this method to get the sustainable development status of resources carrying capacity in Guangdong Province. It has 
aroused the research interest of many experts and scholars, and has been widely used in the evaluation of resource carrying capacity in different regions [Sun, Ye, \& Yu, 2014; Liao, Ji, \& Peng, 2016; Pei \& Wang, 2017; He, 2018; Cai, Zheng, \& Gong, 2018]. In recent years, some scholars believe that my country's traditional relative resource carrying capacity analysis model has incomprehensive factors that affect the research or has made significant improvements to its model research methods, such as Sun Hui [Sun \& Liu, 2014], Huang Changfeng [Huang \& He, 2011], Li Zehong [Li, Dong, \& Tang, 2008], Cao Jianfei [Cao, 2015] and so on. Based on the existing models of predecessors, this research has further modified and improved the model. Compared with other traditional model versions, the relative social resource carrying capacity and the relative ecological environment carrying capacity have been increased, and the relative natural resource environmental carrying capacity model has been greatly expanded to explore the relative resource carrying capacity of the region in a more comprehensive and comprehensive manner. Provide a reliable theoretical basis for the sustainable development of population, resources, environment and society in the Northwest.

\section{Overview of Baoji City}

Baoji is located on the Northern Slope of Qinling Mountains, with geographical coordinates of $106^{\circ} 18^{\prime}-108^{\circ} 03^{\prime} \mathrm{E}$ and $33^{\circ} 35^{\prime}-35^{\circ} 06^{\prime} \mathrm{N}$. Baoji is an important industrial node economic city in northwest and inland areas of China at present. It is located on the economic link of "Guanzhong-Tianshui Economic Development Zone", which is also proposed by the National Development and Reform Commission. "One Belt And One Road" on the important node city economic construction, 8 counties has 4 areas: Jintai area, Weibin district, old area, Fengxiang area four boroughs and zones, too white, Fengxian county, out, our tour, the regionalization, this, the regionalization of 8 counties, the administrative area of land with a total area of 1.81 square kilometers, more than the end of 2019 the population of permanent residents in 3.761 million, one thousand people. Baoji Chinese high latitudes in geography climate of warm temperate zone continental semi-humid monsoon climate, is a temperate continental monsoon climate types, the existing forest vegetation coverage rate $53.78 \%$, there are all kinds of natural tourist destination, such as: the mountain grasslands, such as Qian lake national wetland park, Taibai mountain national forest park and other kinds of tourist attractions, was named national forest, in the city China's excellent tourist city, a mountainous area of 643,000 hectares of woodland. The river system network in Baoji City is arranged with the Qinling Mountains as the main boundary, belonging to the Yellow River and the Yangtze River respectively. It is estimated that the underground water reserves in Baoji can provide about 756 million cubic meters of mined water every year. Baoji has an ideal base for the development of surface quality water sources. Baoji is the heavy industry city in northwest China, the development of industrial economy 
in vulgar mode makes the Baoji ecological environment worsening brings serious ecological problems, Baoji population growth is too large, the intensity of land use with higher and higher, and in recent years, as a result of overgrazing, unreasonable development and utilization, economic development and resource environment is the contradiction between the need to be addressed. The deterioration of ecological environment has seriously hindered the sustainable development among population, economy, resources and environment in Baoji. It is of great significance to study the relationship between resource carrying capacity and population to guarantee the economic development and environmental protection of Baoji City. This paper adopts the relative resource carrying capacity calculation method proposed by scholar Huang Ningsheng to calculate and analyze the resource carrying capacity of Baoji and puts forward reasonable suggestions, in order to provide a scientific theoretical framework for the sustainable development of Baoji's economy, resources and environment. The general situation of Baoji City is shown in Figure 1 below.

\section{Research Methods}

\subsection{Relative Resource Carrying Capacity Model Design}

Referring to existing models, considering that resource carrying capacity is a complex ecosystem closely related to population-nature-economy-society-environment, relative social resource carrying capacity and relative environmental resource

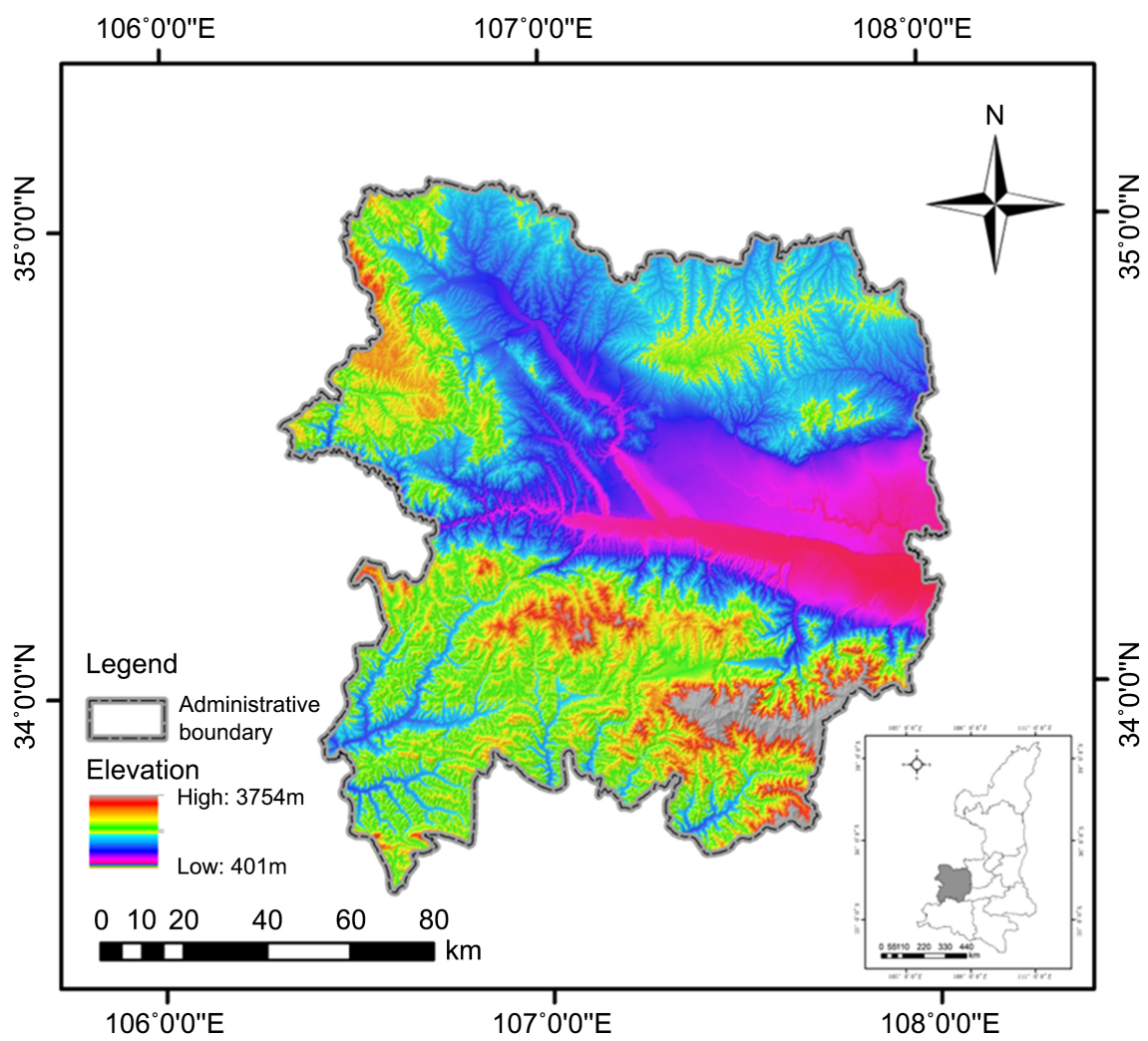

Figure 1. Overview of Baoji city. 
carrying capacity are included. Then, according to the principle of superior resources and restrictive resources in the study area, the grain output and water supply are put into the range of natural resources carrying capacity, and the existing model is improved, so that the model can reflect the relative resources carrying capacity of Baoji City more completely. Finally, farmers' cultivated land area, grain output and total water supply are regarded as important indicators of natural resources, GDP as an important indicator of economic resources, and total retail sales of social consumer goods as an important indicator of social resources. The discharge rate of industrial wastewater is regarded as an important indicator of environmental resources. Compared with geometric mean method, though the summation calculation method of weighted method has greater comprehensive subjectivity, the matching degree of regional comprehensive resources in Baoji City is not high. It is not suitable to use geometric mean method to calculate the corresponding comprehensive carrying capacity of resources in this region, so the weighted summation method is chosen to calculate the relative carrying capacity of resources in Baoji City.

1) The traditional relative resource carrying capacity model

According to the actual situation of resources in Baoji city, cultivated land area and GDP (which represent natural resources and economic resources respectively) are selected as the main analysis indicators, and the calculation formula of relative resource carrying capacity is as follows:

Relative carrying capacity of land resources: $C r=I 1 \times Q 1$, in which, $C r 1$ is the relative carrying capacity of land resources; $I l$ is the land resource carrying index, $I 1=Q p 0 / Q I 0, Q p_{0}$ is the population of the reference area, $Q I_{0}$ is the cultivated land area in the reference area, $Q 1$ is the cultivated land area in the study area.

Relative carrying capacity of economic resources: $C r e=I e \times Q e$, in which, $\mathrm{Cre}$ is the relative carrying capacity of economic resources; Ie is the carrying capacity index of economic resources; Ie $=Q p 0 / Q e 0, Q p 0$ is the population of the reference area, $Q e 0$ for that GDP of the reference area, $Q e$ Gross domestic product of the study area.

Comprehensive bearing capacity: $C s=W r l \times C r L+W r e \times C r e$, in which, $C s$ is the comprehensive bearing capacity; $\mathrm{Wrl}$ is the weight of land resources carrying capacity; Wre is the weight of carrying capacity of economic resources.

2) Improved relative resource carrying capacity model

Relative carrying capacity of natural resources:

$C r n=W l I l Q l+W w I w Q w+W g I g Q g, \quad I l=Q p 0 / Q l 0 ; \quad I w=Q p 0 / Q w 0 ;$

$I g=Q p 0 / Q g 0$; in which, $I l, I w, I g$ they are the carrying index of land resources, water resources and grain output in the reference area; $Q p 0$ is the population of the reference area, $Q l 0, Q w 0, Q g 0$ they are the cultivated land area, total water supply and grain output of the reference area. $\mathrm{Crn}$ for the relative carrying capacity of natural resources, $Q l, Q w, Q g$, they are cultivated land area, total water supply and grain output in the study area. $W l, Q w$, $Q g$ they are the weights of land resources, water resources and grain output in 
the relative carrying capacity of natural resources.

Relative economic resources carrying capacity: economic resources carrying capacity index and relative economic resources carrying capacity. The calculation formula of economic resource carrying index is: $I e=Q p 0 / Q e 0$. In which: Ie for the economic resources carrying index; $Q e 0$ is the gross national product of the reference area. The calculation formula of relative economic resource carrying capacity is: $\mathrm{Crec}=\mathrm{IeQe}$. In which: $\mathrm{Crec}$ is the relative carrying capacity of economic resources; $Q e$ is the gross national product of the study area.

Relative carrying capacity of social resources: carrying index of social consumer goods resources and relative carrying capacity of social resources. The formula for calculating the resource carrying index of social consumer goods is: $I c=Q p 0 / Q c 0$. In which: $I c$ carrying index for social consumer goods resources; $Q c 0$ total retail sales of social consumer goods in the reference area. Relative carrying capacity of social resources: $C r s=I c Q c$. In which: $C r s$ for the relative carrying capacity of social resources; $Q c$ is the total retail sales of social consumer goods in the study area.

Relative environmental resource carrying capacity: environmental resource carrying index and relative environmental resource carrying capacity. The calculation formula of environmental resource carrying index is: Ien $=Q p 0 / Q e n 0$. In which: Ien is the environmental resource carrying index; Qen 0 is the total discharge amount of industrial wastewater in the reference area. The calculation formula of relative environmental resource carrying capacity is: Cren = IenQen . In which, Cren is the relative carrying capacity of environmental resources; Qen is the total amount of industrial wastewater discharged up to standard in the study area. Relative comprehensive resource carrying capacity:

$C s=W r n C r n+W r e c C r e c+W r s C r s+W r e n C r e n, C s$ for the relative comprehensive carrying capacity of resources, according to the resource characteristics of Baoji city, Delphi method is used to determine the weight as follows; $W l=0.5$; $W w=0.2 ; W g=0.3 ; W r n=0.3 ;$ Wrec $=0.3 ;$ Wrs $=0.2 ;$ Wren $=0.2$.

\subsection{The Bearing State Judgment Basis}

Comprehensive bearing index can be used to evaluate the overload, critical and surplus bearing state of relative resource bearing capacity, and the calculation formula is as follows: $R=C s / P$. In which: $R$ is the bearing index; $C s$ is the comprehensive carrying capacity of relative resources; $P$ is the actual population of the study area. $R>105 \%$ when, it is a surplus situation; $95 \% \leq R \leq 105 \%$, for the critical situation; $R<95 \%$, for the overload situation.

\subsection{Data Sources}

Data such as population, cultivated land area, total water supply, grain output, GDP, total retail sales of social consumer goods, and discharge of industrial wastewater are from China Statistical Yearbook, Shaanxi Statistical Yearbook, Baoji Statistical Yearbook, Shaanxi Statistical Bulletin and Baoji Statistical Bulletin from 2010 to 2019. This is shown in Table 1. 
Table 1. Source of data for the study area.

\begin{tabular}{|c|c|}
\hline The name of the data & The data source \\
\hline Population & $\begin{array}{c}\text { China Statistical Yearbook (2010-2019) } \\
\text { Statistical Yearbook of Shaanxi Province (2010-2019) } \\
\text { Baoji Statistical Yearbook (2010-2019) }\end{array}$ \\
\hline Arable land & $\begin{array}{c}\text { China Statistical Yearbook (2010-2019) } \\
\text { Statistical Yearbook of Shaanxi Province (2010-2019) } \\
\text { Baoji Statistical Yearbook (2010-2019) }\end{array}$ \\
\hline The amount of water supply & $\begin{array}{c}\text { China Statistical Yearbook (2010-2019) } \\
\text { Shaanxi Statistical Bulletin (2010-2019) } \\
\text { Baoji Statistical Bulletin (2010-2019) }\end{array}$ \\
\hline Food production & $\begin{array}{c}\text { China Statistical Yearbook (2010-2019) } \\
\text { Statistical Yearbook of Shaanxi Province (2010-2019) } \\
\text { Baoji Statistical Yearbook (2010-2019) }\end{array}$ \\
\hline GDP & $\begin{array}{c}\text { China Statistical Yearbook (2010-2019) } \\
\text { Statistical Yearbook of Shaanxi Province (2010-2019) } \\
\text { Baoji Statistical Yearbook (2010-2019) }\end{array}$ \\
\hline $\begin{array}{l}\text { Total retail sales of } \\
\text { consumer goods }\end{array}$ & $\begin{array}{c}\text { China Statistical Yearbook (2010-2019) } \\
\text { Statistical Yearbook of Shaanxi Province (2010-2019) } \\
\text { Baoji Statistical Yearbook (2010-2019) }\end{array}$ \\
\hline $\begin{array}{l}\text { Industrial waste water } \\
\text { discharge up to standard }\end{array}$ & $\begin{array}{l}\text { China Statistical Yearbook (2010-2019) } \\
\text { Shaanxi Statistical Bulletin (2010-2019) } \\
\text { Baoji Statistical Bulletin (2010-2019) }\end{array}$ \\
\hline
\end{tabular}

\section{Empirical Application Analysis}

\subsection{Comparison before and after Model Application}

In the traditional evaluation model of relative resource carrying capacity in China, the two evaluation module indicators of relative natural resource carrying capacity and relative economic resource carrying capacity are selected as quantitative indicators by selecting regional cultivated land area and regional population GDP value respectively; in the process of traditional model design improvement, Relative water resources and grain yield are added into the evaluation module of relative natural resources, and the influencing factors of social resources and environmental resources are expanded. The comparative value in the model and the calculated results (see Table 2) shows that from 2010 to 2019, when the traditional resource carrying capacity model is used to calculate the resource carrying capacity of Baoji City, the overall trend is in an overload situation. The analysis shows that the average overloaded population is 221,800 ; however, under the calculation results of the improved model, the relative resource carrying capacity of Baoji City is in a state of abundance, and there are 
still 1,467,400 people in Baoji City. According to the evolution of relative resource carrying capacity of Baoji City from 2010 to 2019, the average comprehensive carrying capacity index of Baoji City under the traditional calculation model is 940,900 people. However, under the improved model, it is calculated to be 1,392,400 people. The calculation results show that compared with the traditional model, the carrying capacity of Baoji City is improved to a great extent. In the traditional model analysis, the comprehensive carrying index and carrying capacity of Baoji City are greatly reduced, it shows that the resource carrying capacity of Baoji City is declining with the increasing social population of Baoji City. However, the comprehensive load-bearing index calculated under the improved model increased significantly. It further illustrates that with the rapid economic development of Baoji since the reform and opening up, the share of economic resources and social resources in resource carrying has increased and the carrying capacity has become increasingly prominent.

Table 2. Relative resource carrying capacity of Baoji under traditional model and improved model.

\begin{tabular}{|c|c|c|c|c|c|c|c|c|c|}
\hline \multirow[b]{2}{*}{ year } & \multirow[b]{2}{*}{$\begin{array}{c}\text { P0/ten } \\
\text { thousand } \\
\text { people }\end{array}$} & \multicolumn{4}{|c|}{ Traditional model } & \multicolumn{4}{|c|}{ Improved model } \\
\hline & & $\begin{array}{l}\text { Cs/ten } \\
\text { thousand } \\
\text { people }\end{array}$ & $\begin{array}{l}\mathrm{P} / \text { ten } \\
\text { thousand } \\
\text { people }\end{array}$ & $\mathrm{R} / \%$ & $\begin{array}{l}\text { Bearing } \\
\text { state }\end{array}$ & $\begin{array}{l}\text { Cs/ten } \\
\text { thousand } \\
\text { people }\end{array}$ & $\begin{array}{l}\mathrm{P} / \text { ten } \\
\text { thousand } \\
\text { people }\end{array}$ & $\mathrm{R} / \%$ & $\begin{array}{l}\text { Bearing } \\
\text { state }\end{array}$ \\
\hline 2010 & 371.67 & 352.69 & 18.98 & 94.9 & overburden & 785.52 & -413.85 & 211.35 & $\begin{array}{c}\text { more than } \\
\text { enough }\end{array}$ \\
\hline 2011 & 372.72 & 356.6 & 16.12 & 95.7 & overburden & 715.9 & -343.18 & 192.07 & $\begin{array}{c}\text { more than } \\
\text { enough }\end{array}$ \\
\hline 2012 & 373.67 & 374.16 & -0.49 & 100 & critical & 483.94 & -110.27 & 129.51 & $\begin{array}{c}\text { more than } \\
\text { enough }\end{array}$ \\
\hline 2013 & 374.46 & 369.05 & 5.41 & 98.6 & overburden & 449.56 & -75.1 & 120.06 & $\begin{array}{c}\text { more than } \\
\text { enough }\end{array}$ \\
\hline 2014 & 375.32 & 353.94 & 21.38 & 94.3 & overburden & 483.56 & -108.24 & 128.84 & $\begin{array}{c}\text { more than } \\
\text { enough }\end{array}$ \\
\hline 2015 & 376.33 & 359.03 & 17.3 & 95.4 & overburden & 488.67 & -112.34 & 129.85 & $\begin{array}{c}\text { more than } \\
\text { enough }\end{array}$ \\
\hline 2016 & 377.5 & 354.11 & 23.39 & 93.8 & overburden & 493.08 & -115.58 & 130.62 & $\begin{array}{c}\text { more than } \\
\text { enough }\end{array}$ \\
\hline 2017 & 378 & 354.63 & 23.37 & 93.8 & overburden & 458.57 & -80.57 & 121.31 & $\begin{array}{c}\text { more than } \\
\text { enough }\end{array}$ \\
\hline 2018 & 377.1 & 319.81 & 57.29 & 84.8 & overburden & 433.43 & -56.33 & 114.94 & $\begin{array}{c}\text { more than } \\
\text { enough }\end{array}$ \\
\hline 2019 & 376.1 & 337.08 & 39.02 & 89.6 & overburden & 428.03 & -51.93 & 113.81 & $\begin{array}{c}\text { more than } \\
\text { enough }\end{array}$ \\
\hline $\begin{array}{l}\text { average } \\
\text { value }\end{array}$ & 375.29 & 353.11 & 22.18 & 94.09 & overburden & 522.026 & -146.74 & 139.24 & $\begin{array}{c}\text { more than } \\
\text { enough }\end{array}$ \\
\hline
\end{tabular}




\subsection{Application Analysis of the Improved Model Taking the Whole Country as the Reference Area}

\subsubsection{Analysis of the Evolution of the Carrying Capacity of Various Resources}

Taking the whole country as a reference area, from the analysis of Table 3 and Figure 2, it can be concluded that the resource carrying capacity of Baoji City changed obviously in 2010-2012, with little change in other years. The carrying capacity of economic resources accounts for the largest proportion in the comprehensive carrying capacity of resources, with an average contribution rate of $36 \%$, while the average contribution rate of social resources to the comprehensive carrying capacity of resources is $29.8 \%$, showing an overall upward trend. The number rose from 2,601,200 in 2010 to 3,201,200 in 2019, and natural resources and environmental resources accounted for a small proportion in the comprehensive carrying capacity of resources, with average contribution rates of $16.3 \%$ and $17.9 \%$ respectively, indicating that Baoji people reduced their dependence on cultivated land resources, paid attention to the development of secondary and tertiary industries, and enhanced their awareness of environmental protection. The results show that since the establishment of Guanzhong-Tianshui Economic Zone Economic Belt in 2009, the economic development of Baoji City has been greatly promoted. Natural resources such as land, water resources and grain output are no longer the important carrying capacity of the population of Baoji City. With the continuous urbanization process and economic development of Baoji City, the carrying capacity of economic and social resources to the ever-increasing population of Baoji City has gradually become stronger. However, the carrying capacity of environmental resources to population is not very significant in the proportion of comprehensive resources carrying capacity.

Table 3. Relative resource carrying capacity of Baoji City in 2010-2019 with the whole country as reference area.

\begin{tabular}{ccccccccccc}
\hline year & Crn & Cre & Crc & Cren & Cs & P0 & P & R/\% & Bearing state \\
\hline 2010 & 175.55 & 317.59 & 260.12 & 817.77 & 785.52 & 371.67 & -413.85 & 211.35 & more than enough \\
2011 & 163.75 & 324.66 & 259.9 & 683.46 & 715.9 & 372.72 & -343.18 & 192.07 & more than enough \\
2012 & 167.72 & 354.45 & 263.93 & 116.63 & 483.94 & 373.67 & -110.27 & 129.51 & more than enough \\
2013 & 165.05 & 354.75 & 268.92 & 124.3 & 449.56 & 374.46 & -75.1 & 120.06 & more than enough \\
2014 & 155.61 & 353.76 & 279.19 & 99.85 & 483.56 & 375.32 & -108.24 & 128.84 & more than enough \\
2015 & 157.38 & 358.4 & 279.94 & 98.87 & 488.67 & 376.33 & -112.34 & 129.85 & more than enough \\
2016 & 157.19 & 361 & 292.16 & 110.81 & 493.08 & 377.5 & -115.58 & 130.62 & more than enough \\
2017 & 156.81 & 369.19 & 303.96 & 74.43 & 458.57 & 378 & -80.57 & 121.31 & more than enough \\
2018 & 135.91 & 341.78 & 316.66 & 50.42 & 433.43 & 377.1 & -56.33 & 114.94 & more than enough \\
2019 & 150.27 & 313.17 & 320.12 & 50.42 & 428.03 & 376.1 & -51.93 & 113.81 & more than enough \\
average value & 158.52 & 344.87 & 284.49 & 222.7 & 522.03 & 375.29 & -146.74 & 139.24 & more than enough \\
\hline
\end{tabular}




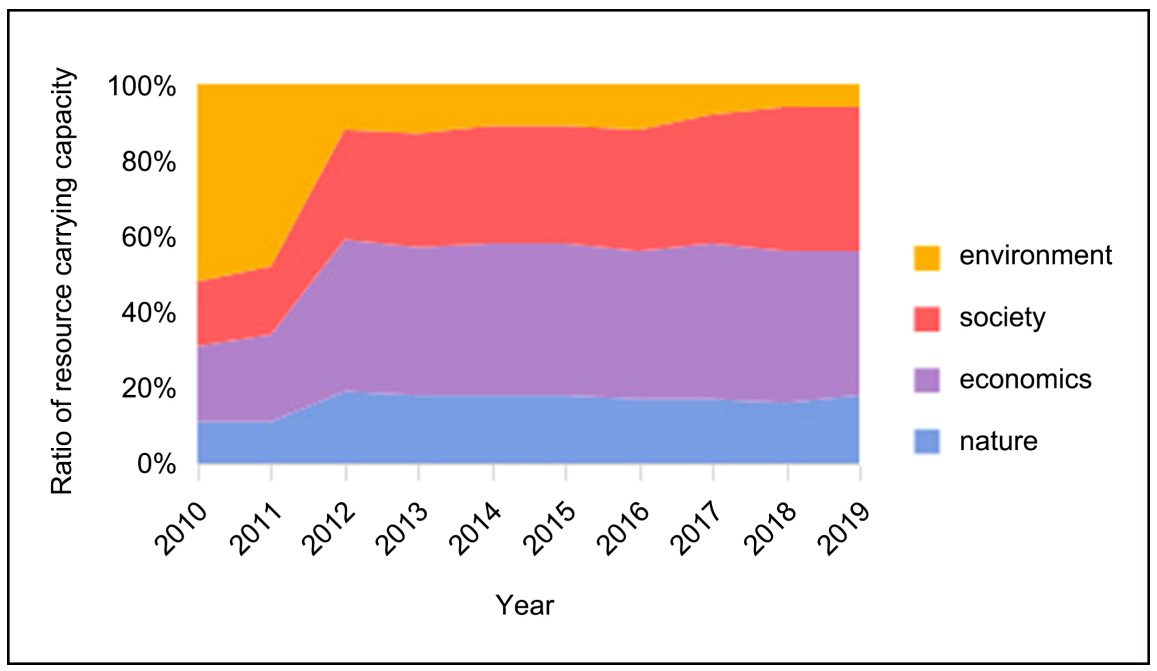

Figure 2. Evolution trend of relative resource carrying capacity in Baoji City with the whole country as reference area.

\subsubsection{Evolution Analysis of Comprehensive Carrying Capacity of Relative Resources}

The calculation results in Table 3 show that the relative resource carrying capacity of Baoji City is in a surplus state from 2010 to 2019. The data show that the average comprehensive resource carrying capacity is $1,467,400$ people, and the surplus quantity of the relative resource carrying capacity is declining. The maximum surplus population in 2010 is $4,138,500$ people, which has dropped sharply to 519,300 people in 2019 . During these 10 years, the carrying capacity of surplus scale and the number of surplus population is relatively large, and the comprehensive carrying capacity index shows a declining trend under the influence of the number of surplus scale population. However, the surplus situation of Baoji's comprehensive resource carrying capacity has always remained stable. The trend of data development shows that with the population growth in Baoji, The surplus scale of Baoji's current relative comprehensive resource carrying capacity is not enough to carry the future urban population demand of Baoji.

\subsection{Application Analysis of Improved Model Taking Shaanxi as Reference Area}

\subsubsection{Analysis of the Evolution of the Carrying Capacity of Various Resources}

From the analysis of Table 4 and Figure 3, it can be seen that, taking Shaanxi Province as a reference area, the gap between the carrying capacity of each resource and that of the whole country is obviously reduced. When the value of Shaanxi Province is taken as the main reference value, the proportion gap of each resource carrying capacity in the total resource carrying capacity system gradually decreases, the proportion of natural resources carrying capacity, economic resources carrying capacity, social resources carrying capacity and environmental resources carrying capacity in the comprehensive resources carrying capacity gradually tends to a balanced development state. The average contribu- 
tion rate of relative economic resources carrying capacity is $23.9 \%$, and that of social resources carrying capacity is $21.7 \%$. Compared with the whole country, the contribution rate of relative economic resources carrying capacity and relative social resources carrying capacity in relative comprehensive resources carrying capacity has greatly decreased, and the proportion of relative natural resources carrying capacity and relative environmental resources carrying capacity in Baoji City has obviously increased greatly, with the average contribution rate reaching $25.6 \%$ and $28.8 \%$. It shows that the main carrying capacity of population resources in Baoji City is mainly natural resources.

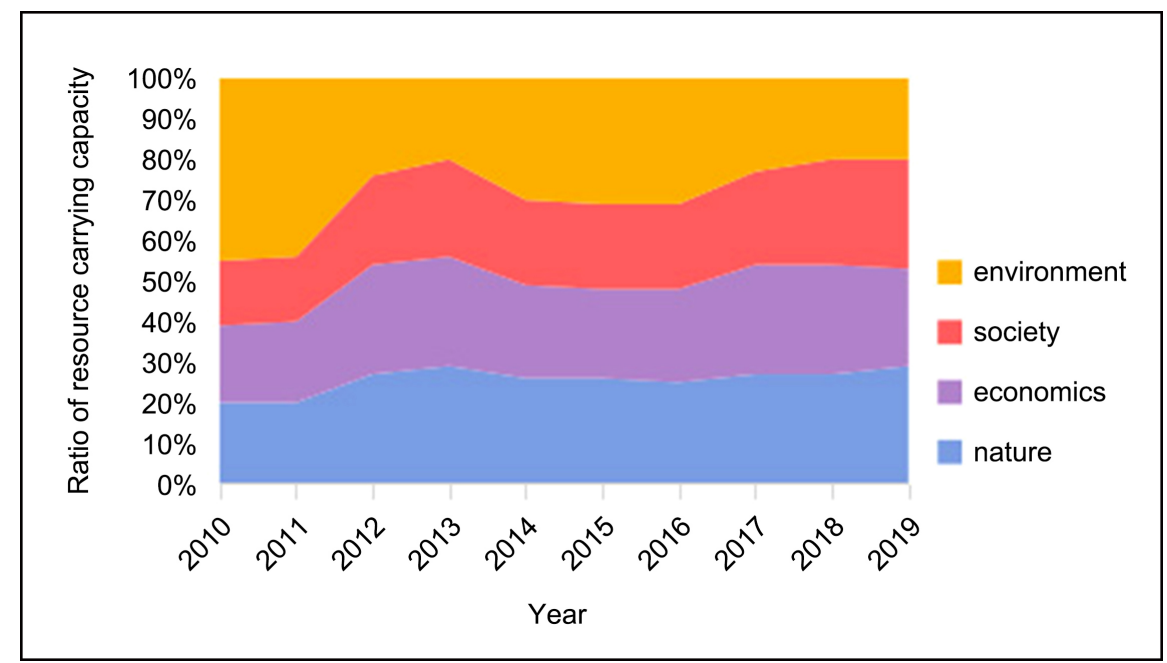

Figure 3. Evolution trend of relative resource carrying capacity in Baoji City with Shaanxi Province as reference area.

Table 4. Relative resource carrying capacity of Baoji city in Shaanxi province from 2010 to 2019.

\begin{tabular}{ccccccccccc}
\hline year & Crn & Cre & Crc & Cren & Cs & P0 & P & R/\% & Bearing state \\
\hline 2010 & 452.9 & 445.28 & 360.61 & 1042.09 & 1150.44 & 371.67 & -778.77 & 309.53 & more than enough \\
2011 & 425.02 & 433.79 & 349.63 & 932.94 & 1070.69 & 372.72 & -697.97 & 287.26 & more than enough \\
2012 & 435.47 & 421.76 & 354.3 & 384.74 & 798.13 & 373.67 & -424.46 & 213.59 & more than enough \\
2013 & 430.68 & 401.41 & 357.16 & 287.7 & 738.48 & 374.46 & -364.02 & 197.21 & more than enough \\
2014 & 433.74 & 385.23 & 361.75 & 514.33 & 847.53 & 375.32 & -472.21 & 225.82 & more than enough \\
2015 & 437.95 & 381.68 & 351.69 & 525.61 & 848.47 & 376.33 & -472.14 & 225.26 & more than enough \\
2016 & 431.53 & 406.65 & 364.71 & 541.1 & 871.99 & 377.5 & -494.49 & 230.99 & more than enough \\
2017 & 431.09 & 428.44 & 370.76 & 368.36 & 799.33 & 378 & -421.33 & 211.46 & more than enough \\
2018 & 376.56 & 386.18 & 370.96 & 282.06 & 707.87 & 377.1 & -330.77 & 187.71 & more than enough \\
2019 & 413.01 & 351.61 & 380.16 & 284.19 & 714.49 & 376.1 & -338.39 & 189.97 & more than enough \\
\hline average value & 426.795 & 404.2 & 362.17 & 516.31 & 552.82 & 375.287 & -479.46 & 227.88 & more than enough \\
\hline
\end{tabular}




\subsubsection{Evolution Analysis of Comprehensive Carrying Capacity of Relative Resources}

It can be seen from Table 4 that in 2010-2019, when Shaanxi Province was used as a reference area to analyze and calculate the relative resource carrying capacity, the average comprehensive resource carrying capacity of Baoji City was 4,794,600 people, and the surplus state of the comprehensive resource carrying capacity remained unchanged, but the surplus scale decreased continuously, from 7,787,700 people in 2010 to 3,383,900 people in 2019. The load-bearing index also dropped rapidly from 309.53 in 2010 to 189.97 in 2019. It shows that with the rapid urbanization of Baoji City, resources and population will eventually be out of balance. Compared with the whole country, the relative comprehensive carrying capacity of resources, the size of surplus population and the carrying index of Baoji City, which takes Shaanxi Province as the reference area, have dropped significantly.

\section{Conclusion and Discussion}

\subsection{Conclusion}

In this paper, Baoji city in northwest arid area is taken as the research scope. According to the resource characteristics of Baoji city in the research area, considering the comprehensiveness of influencing factors of relative resource carrying capacity on the basis of previous research on resource carrying capacity model, the influencing factors of natural resources are expanded by adding water resources, grain output, social resources and environmental resources, The supporting role of environmental resources carrying capacity and social resources carrying capacity on regional resources carrying capacity reflects the difference of regional resources carrying capacity and the important influence of various resources on the quality of life and development of population. And focus on increasing the city's relative comprehensive carrying capacity of social resources and relative comprehensive carrying capacity of environmental resources. 1) from 2010 to 2019, Taking the whole country as a reference area, this paper makes a quantitative analysis of the relative resource carrying capacity index of Baoji City by using the traditional analysis model of resource carrying capacity in China, and finds that the comprehensive carrying capacity of relative resources has been in a high overload state. However, based on the latest improved analysis model of relative resource carrying capacity, after analyzing and calculating the relative resource carrying capacity index of Baoji City, it is concluded that the comprehensive carrying capacity of relative resources of Baoji City has always been in a high surplus state. In the carrying capacity of Baoji's social population, Economic resources carrying capacity and social resources carrying capacity have the largest contribution rate in comprehensive carrying capacity. The carrying capacity of environmental resources and natural resources is relatively reduced. 2) When Shaanxi Province is taken as the reference area, the contribution of each resource carrying capacity to the comprehensive resource 
carrying capacity is relatively balanced, while the natural resource carrying capacity has not changed much, from $452.5 \%$ in 2010 , from 90,000 to $4,130,100$ in 2019. Compared with the whole country as a reference area, the carrying capacity of various resources in Baoji City is in a stable state, and the carrying capacity of various resources is relatively balanced, while the contribution rate of economic resources carrying capacity and social resources carrying capacity to comprehensive carrying capacity is significantly reduced. The number of surplus population with comprehensive resource carrying capacity is reduced, The resource carrying index is declining. It can be seen from Figure 3 that the resource carrying capacity presents an inverted $U$ shape, which was the inflection point of the growth of various resource carrying capacity in Baoji City in 2011. After that, the carrying capacity of various resources in Baoji City increased rapidly, stabilized after a downward trend in 2013, and started to rise again in 2016, showing a positive U-shaped growth. Taking Shaanxi Province as a reference area, the contribution rate of economic resources carrying capacity has declined compared with that of the whole country, indicating that Baoji's economic development still lags behind the national average level.

\subsection{Discussion}

Relative resource carrying capacity is a complex driving capacity complex under the interaction of many advantageous resource driving factors. Based on the principle of the traction effect of superior resources and the binding effect of inferior resources, the grain yield and water resources are included in the carrying capacity of natural resources in Baoji City, and the supporting capacity of the carrying capacity of natural resources is expanded. The proportion of natural resources carrying capacity in comprehensive resources carrying capacity increases, and the contribution rate also increases. The carrying capacity of social resources is introduced in the influence of social factors and environmental factors. Therefore, compared with the traditional model and the improved model, it has richer carrying capacity. When using the improved model to analyze the resource carrying capacity of Baoji City, The carrying capacity of resources in Baoji City is in a surplus state, but the number of surplus population fluctuates greatly from 2010 to 2019, which can reflect that the carrying capacity of natural, economic, social and environmental resources to the social population of Baoji City gradually weakens with the development of economy and society and the growth of the actual population in recent years. In the process of analyzing the resources carrying capacity, it is found that the economic and social resources carrying capacity account for the largest contribution to the comprehensive carrying capacity of resources in Baoji City, while the natural and environmental resources account for a low proportion, indicating that Baoji City has developed well in economy and society in recent years, and its awareness of environmental protection has increased. It is in a stage of harmonious development of population-economy-society-environment, but the index of resource carrying capacity 
decreases. The surplus scale has dropped sharply. It shows that the carrying capacity of various resources in Baoji City obviously cannot reasonably carry the actual population of Baoji City. Therefore, in order to match the future development of Baoji City, the following suggestions are put forward. 1) Strengthen the protection of farmland. Scientific and rational allocation and structural optimization of existing land resources can improve land use efficiency, increase grain output and increase the contribution rate of natural resources to comprehensive carrying capacity. 2) Establish a perfect population management system, control the growth of population, enhance the national quality education, improve the cultural level, and alleviate the pressure of the growing population. Adhering to the family planning policy advocated by the state can effectively control the population growth and make rational planning and migration of the population. 3) Develop and utilize energy reasonably and efficiently to improve energy efficiency. Establish a security system for sustainable utilization of resources and a security system for strategic reserve of important resources. 4) Baoji is a heavy industry city, so it should change the extensive economic development mode. Introducing high-tech industries and new industries, adjusting the previous industrial model and changing the mode of economic growth, so as to guide the regional economic development of Baoji City. Sustainable development based on population-economy-environment depends not only on one or both of them, but also on in-depth coordination of their mutual relations and overall consideration of all aspects. Healthy development under the reasonable guidance of the scientific concept of development is indispensable. Only in this way can Baoji achieve the goal of stable, balanced and sustainable development in the future.

\section{Fund Project}

Soft Science Project of Zhejiang Science and Technology Department (2018C35063); in 2019, the key project of Zhejiang Province's philosophy and social science planning project took Zhejiang Province as an example (19NDJC003Z).

\section{Conflicts of Interest}

The authors declare no conflicts of interest regarding the publication of this paper.

\section{References}

Cai, K., Zheng, K., \& Gong, Z. (2018). Study on the Utilization of Community Grassland Resources in Mount Qomolangma Nature Reserve Based on Resource Carrying Capacity. China Population, Resources and Environment, 28, 194-197.

Cao, J. (2015). Improvement and Prediction of Relative Resource Carrying Capacity Model. Statistics and Decision, 15, 29-32.

Chen, T., Tong, Y., \& Zeng, X. (2008). Analysis of Shenzhen Population Carrying Capacity and Countermeasures. Northwest Population, 29, 27-30, 37.

Han, P., Liu, C., \& Yang, F. (2008). Fuzzy Comprehensive Evaluation of Water Resources 
Carrying Capacity in Kaifeng City. People's Yellow River, 30, 45-46, 49.

He, Q. (2018). Construction of Resource and Environmental Carrying Capacity Index System in the Pearl River. Chinese Journal of Agricultural Resources and Regional Planning, 7, 99-105.

Hou, X., \& Sun, X. (2002). Study on the Potential of Cultivated Land Grain Production and Population Carrying Capacity-A Case study of Changqing County. Geoscience, 4, 24-29.

Huang, C., \& He, L. (2011). Improvement of Relative Resource Carrying Capacity Model and Its Empirical Analysis. Resources Science, 33, 41-49.

Huang, N., \& Kuang, Y. (2000). Relative Resource Carrying Capacity and Sustainable Development in Guangdong. Journal of Economic Geography, 20, 52-56.

Li, Z., Dong, S., \& Tang, S. (2008). Improvement of Relative Resource Carrying Capacity Model and Its Empirical Analysis. Resources Science, 30, 1336-1342.

Liao, H., Ji, Y., \& Peng, S. (2016). Resources and Environmental Carrying Capacity and Regional Sustainable Development. Ecology and Environment, 25, 1253-1258.

Lu, Y. (2014). Study on Sustainable Development of Western Region Based on Relative Resource Carrying Capacity. Social Sciences in Yunnan, 4, 89-92.

Pei, W., \& Wang, X. (2017). Study on the Change of Relative Resource Carrying Capacity and Sustainable Development of Tianshui City. Resources Development and Market, 5.

Sun, F., Ye, Y., \& Yu, B. (2014). Study on Resource and Environment Carrying Capacity Assessment of Dapeng Peninsula in Guangdong Province. Ecological Science, 33, 1194-1199. (In Chinese with English Abstract)

Sun, H., \& Liu, Y. (2014). Expansion and Demonstration of Relative Resource Carrying Capacity Model. China Population Resources and Environment, 24, 126-135.

Wei, Y., \& Chang, J. (2014). Research on Population Carrying Capacity of Land Resources in Shandong Province Based on System Dynamics. Journal of Shandong Normal University (Natural Science Edition), 29, 93-97, 102.

Zhang, A. (2000). Guangxi Relative Resource Carrying Capacity and Sustainable Development. Academic Forum, 4, 53-56.

Zhao, X., Zhou, G., \& Sui, X. (2009). Study on Population Carrying Capacity of Liaoning Province. Journal of Meteorology and Environment, 25, 61-65. 